\title{
Measurement of Sap Flow Dynamics Through the Tomato Peduncle Using a Non-invasive Sensor Based on the Heat Field Deformation Method
}

Jochen Hanssens, Tom De Swaef and Kathy Steppe

Laboratory of Plant Ecology, Department of Applied Ecology and Environmental Biology, Faculty of Bioscience Engineering, Ghent University, Ghent

Belgium

Nadezhda Nadezhdina

Institute of Forest Ecology, Mendel University of Agriculture and Forestry, Brno, Czech Republic

Keywords: tomato, sap flow, heat field deformation, sensor, peduncle, xylem, phloem

\begin{abstract}
Recent contradicting evidence on the contributions of xylem and phloem to tomato fruit growth highlights the need for a more thorough insight into the dynamics of sap flow through the tomato peduncle. In fact, knowledge on sap flow dynamics through small plant parts remains scarce, due to a lack of direct measurements. Most currently available sap flow sensors use needles, making them inappropriate for the direct measurement of sap flow through small plant parts such as a tomato peduncle. Therefore, a non-invasive sap flow sensor based on the heat field deformation (HFD) principle was tested on the peduncle of a tomato truss. This mini HFD sensor, consisting of a heater element and three thermocouples stitched on insulation tape, was wrapped around the peduncle and allowed continuous monitoring of changes in the heat field around the heater caused by sap flow. Actual influx into the tomato truss was calculated based on fruit growth data and estimates of fruit transpiration and was compared with the dynamics measured with the mini HFD sensor. Additionally, heat girdling of the peduncle was performed to block phloem influx to study the dynamics of xylem and phloem influx using the mini HFD sensor. First results of the mini HFD sensor were promising and the measured sap flow dynamics through the tomato peduncle agreed well with the calculated sap influx. Results of the girdling experiment suggested opposite patterns of xylem and phloem influx, with a decreased xylem influx during the daytime. Furthermore, the pattern of xylem influx revealed a close relation with the total water potential in the stem. As such, the mini HFD sensor provided direct measurements of sap flow dynamics through a tomato peduncle and, hence, has a large potential to finally resolve the controversy on water influx into developing fruits.
\end{abstract}

\section{INTRODUCTION}

The importance of plant water status to guarantee a good production and quality of greenhouse tomato (Solanum lycopersicum L.) has been emphasized by many authors (Mitchell et al., 1991; Johnson et al., 1992; Cuartero and Fernandez-Munoz, 1999; De Swaef et al., 2012). Tomato fruit growth results from the influx of water, carbon and minerals through the xylem and the phloem, which is driven by a gradient in hydrostatic and osmotic potential between the stem and the fruit. It is generally acknowledged that 
the phloem accounts for $80-90 \%$ of the influx, whereas the xylem only has a minor contribution (Ehret and Ho, 1986; Ho et al., 1987; Plaut et al., 2004; Guichard et al., 2005). Recently, Windt et al. (2009) used magnetic resonance imaging (MRI) to study water flow into developing tomato fruits and demonstrated that xylem influx accounted for at least $75 \%$ of the net influx. This is contradictory to most of the previous results and highlights the need for a more thorough understanding of the dynamics of sap flow through the tomato peduncle. In fact, knowledge on the dynamics of sap flow through small plant parts such as a tomato peduncle is still limited, since most of the currently available sap flow sensors are only suitable for stems or branches of greater dimension and as such, direct measurements of the sap flow through a tomato peduncle remain scarce. The main limitation of these sensors for use on small plant parts is the use of needles which have to be inserted into the sapwood. Additionally, current sap flow sensors, which are externally installed on the plant, do not allow measurement of small sap flow values (Smith et al., 1999; Sakuratani et al., 1999) or need a period of zero sap flow for calibration. Recently, Clearwater et al. (2009) developed an external heat pulse method for the measurement of sap flow through pedicels of developing kiwifruit. This method proved well for measuring the small sap flow towards the kiwifruits, but a plant specific empirical calibration of the sensor was needed.

In this study, a non-invasive sap flow sensor based on the heat field deformation (HFD) method (Nadezhdina et al., 1998; Nadezhdina et al., 2012) was developed and used to study the dynamics of sap flow through the peduncle of tomato plants grown in light and shade conditions. Sap flow dynamics measured with this mini HFD sensor were compared with calculations of water influx based on continuous measurements of fruit growth and estimates of fruit transpiration. Additionally, heat girdling of the peduncle was performed to distinguish xylem and phloem flow towards the developing fruits and an attempt was made to measure the dynamics of xylem influx with the mini HFD sensor.

\section{MATERIALS AND METHODS \\ Sensor design}

The gauge used in this study was based on the heat field deformation (HFD) principle. These sensors typically make use of four needles, which are inserted into the stem (Nadezhdina et al., 1998; Nadezhdina et al., 2012). One of the needles is continuously heated, and thus creates a heat field in the stem tissue, which is altered by variations in sap flow. The remaining three needles serve as temperature sensors and, as such, monitor the shape of the heat field. However, the use of needles makes this sensor inappropriate for measuring the dynamics of sap flow through small plant parts. Therefore, this sensor was adapted and a non-invasive prototype, based on the same principles of heat field deformation, was developed. Fig. 1 gives a conceptual representation of the sensor configuration. A heater element $(\mathrm{H}$; electrical resistance of $100 \Omega$ ) and three thermocouples ( $\mathrm{T}_{1-3}$; copper-constantan thermocouple) were firmly sewed onto rubber foam insulation tape. The thermocouple configuration allows the measurement of two temperature differences: the symmetrical temperature difference $\left(\mathrm{dT}_{\mathrm{s}}\right)$, measured by the axial thermocouples $\mathrm{T}_{1}$ and $\mathrm{T}_{2}$ and the asymmetrical temperature difference $\left(\mathrm{dT}_{\mathrm{a}}\right)$, measured by the tangential thermocouples $\mathrm{T}_{2}$ and $\mathrm{T}_{3}$. In accordance to Nadezhdina et al. (2012), a third temperature difference $\left(\mathrm{dT}_{\mathrm{s}-\mathrm{a}}\right)$ was calculated as $\mathrm{dT}_{\mathrm{s}}$ minus $\mathrm{dT}_{\mathrm{a}}$. The axial thermocouples were positioned at $10 \mathrm{~mm}$ from the center $\left(\mathrm{Z}_{\mathrm{ax}}\right)$ of the heater element, while the tangential thermocouple $T_{3}$ was located at $3 \mathrm{~mm}\left(Z_{\mathrm{tg}}\right)$ from the center of the heater. A continuous voltage of $3 \mathrm{~V}$ was applied to the heater. 


\section{Plant material and experimental setup}

Tomato plants (Solanum lycopersicum L. 'Admiro') were sown on 1 February 2011, transplanted into rockwool slabs (Master; Grodan, Hedehusene, Denmark) on 23 March 2011 and placed in a small greenhouse compartment $(2 \times 2.5 \times 4 \mathrm{~m})$ at the Laboratory of Plant Ecology, Ghent, Belgium. A trickle irrigation system provided the plants with nutrient solution $\left(\mathrm{EC}=2.7 \pm 0.05 \mathrm{mS} \mathrm{cm}^{-1}\right)$. All trusses were pruned to three fruits per truss and side-shoots were removed according to commercial practice. In total, 12 plants were grown, six of which were placed under a shade screen (TFE PH 77 O, Bonar TF, Zele, Belgium).

Fruit growth was continuously monitored using linear variable displacement transducers (LVDT; Model 2.5 DF, Solartron Metrology, Bognor Regis, UK; accuracy $\pm 2.5 \mu \mathrm{m}$ ), which were attached to the first fruit of the truss by means of custom-made stainless steel holders. Fruit water content $\left(\mathrm{W}^{\mathrm{fr}}, \mathrm{g}\right)$ was calculated from fruit diameter $\left(\mathrm{D}^{\mathrm{fr}}\right.$, $m)$ based on a predetermined empirical relation $\left(n=257 ; R^{2}=0.9949 ; p<0.0001\right)$ :

$$
W^{f r}=26.5 \cdot 10^{5} \cdot D^{f r^{2.8212}}
$$

An empirical correlation between fruit fresh mass and fruit surface then allowed estimating fruit transpiration according to Leonardi et al. (1999). The actual water influx was finally calculated as the sum of fruit transpiration and the change of fresh mass. Measurements of fruit growth started at approximately 35 days after anthesis.

Sap flow of plants in the light and the shade compartment was monitored with heat balance sap flow sensors (Model SGA10-WS, Dynamax Inc., Houston, TX, USA; accuracy $\sim 10 \%$ ), installed below the first leaf according to the installation manual (van Bavel \& van Bavel, 1990). Total xylem water potential in the stem was calculated based on the flow-resistance concept (van den Honert, 1948):

$$
\Psi_{T}^{x}=\Psi_{\text {substrate }}-F_{x} \cdot R^{x}
$$

in which $\Psi_{\mathrm{T}}{ }^{\mathrm{x}}$ is the total water potential in the xylem $(\mathrm{MPa}), \Psi_{\text {substrate }}$ the water potential in the substrate $(-0.08 \mathrm{MPa}), \mathrm{F}_{\mathrm{x}}$ the measured sap flow $\left(\mathrm{g} \mathrm{h}^{-1}\right)$ and $\mathrm{R}_{\mathrm{x}}$ the hydraulic resistance in the xylem compartment $\left(0.0025 \mathrm{MPa} \mathrm{h} \mathrm{g}^{-1}\right)$. In addition, the mini HFD sensor was installed at the base of four truss peduncles in the shade as well as in the light compartment to measure the dynamics of sap flow towards the fruits. Therefore, the rubber foam insulation tape, on which the heater and thermocouples were attached, was carefully wrapped around the peduncle and well insulated.

In order to distinguish between the xylem and the phloem influx into the tomato truss, heat-girdling of the peduncle was performed according to the technique of Guichard et al. (2005). This technique destroys the phloem, thereby blocking phloem influx. Differences in sap flow dynamics between girdled and intact trusses were studied with the mini HFD sensor. All sensor signals were logged at 30-s intervals and averaged every five minutes (CR1000, Campbell Scientific Inc., Logan, Utah, USA).

\section{RESULTS AND DISCUSSION Determination of the $K$ value}


For commercial HFD sensors, the sap flux density is typically calculated as (Nadezhdina et al., 2012):

$$
\mathrm{q}=3600 \mathrm{D}_{\mathrm{st}}\left(\mathrm{K}+\mathrm{dT}_{\mathrm{s}-\mathrm{a}}\right) \mathrm{dT}_{\mathrm{a}}^{-1} \mathrm{Z}_{\mathrm{ax}} \mathrm{Z}_{\mathrm{tg}}{ }^{-1} \mathrm{~L}_{\mathrm{sw}}{ }^{-1},
$$

with $\mathrm{q}$ the sap flux density $\left(\mathrm{cm}^{3} \mathrm{~cm}^{-2} \mathrm{~h}^{-1}\right), \mathrm{D}_{\mathrm{st}}$ the thermal diffusivity of the sapwood $\left(\mathrm{cm}^{2}\right.$ $\left.\mathrm{s}^{-1}\right), \mathrm{Z}_{\mathrm{ax}} \mathrm{Z}_{\mathrm{tg}}{ }^{-1}$ a factor which corrects for the positioning of the needles and $\mathrm{L}_{\mathrm{sw}}$, the sapwood depth $(\mathrm{cm})$. In this formula, $\left(\mathrm{K}+\mathrm{dT}_{\mathrm{s}-\mathrm{a}}\right) \mathrm{dT}_{\mathrm{a}}^{-1}$ represents the dynamic part, which is affected by the actual sap flux density. The parameter $\mathrm{K}$ is the absolute value of $\mathrm{dT}_{\mathrm{s} \text {-a }}$ when sap flow is zero. However, $\mathrm{K}$ can also be calculated in the absence of zero flow conditions, after plotting $\mathrm{dT}_{\mathrm{s}-\mathrm{a}}$ as a function of $\mathrm{dT}_{\mathrm{s}} / \mathrm{dT}_{\mathrm{a}}$. The intersection with the $\mathrm{y}$-axis gives the value of $\mathrm{dT}_{\mathrm{s}-\mathrm{a}}$ in absence of sap flow $\left(\mathrm{dT}_{\mathrm{s}}\right.$ and $\mathrm{dT}_{\mathrm{s}} / \mathrm{dT}_{\mathrm{a}}$ equal $0^{\circ} \mathrm{C}$ ) and as such represents the $\mathrm{K}$ value. Determination of the $\mathrm{K}$ value of the mini HFD sensor is illustrated in Fig. 2A and B for a sensor on a truss of a plant in the light and the shade compartment, respectively. The different $\mathrm{K}$ values of the sensors in the light and the shade compartment might have been a consequence of differences in peduncle diameter, sensor construction and insulation. However, when properly installed, the $\mathrm{K}$ value of the sensor remained fairly constant throughout the measurement period.

\section{Sap flow dynamics through an intact tomato peduncle}

After determination of the $K$ value, sap flow dynamics $\left(\left(\mathrm{K}+\mathrm{dT}_{\mathrm{s}-\mathrm{a}}\right) \mathrm{dT}_{\mathrm{a}}{ }^{-1}\right)$ were calculated for both mini HFD sensors and compared to the calculated sap influx (Fig. 3). A good agreement was found between the HFD dynamics (grey dots) and the calculated actual sap flux (black line) for both the light and the shade plants on two consecutive days in May 2011. The first day was a warm and sunny day, whereas the second day was colder and overcast. The sap flow dynamics as well as the calculated influx indicate a higher total influx on a sunny day compared to a cloudy day (Fig. 3A). Also, influx is markedly higher during the afternoon and evening, than at night and in the morning, which is consistent with the results from Ehret and Ho (1986), Pearce et al. (1993) and Guichard et al. (2005), who found higher growth rates during the day. Reducing radiation with a shade screen also reduced the sap flow towards the truss. Similar results were found for apple trees where shading reduced the influx, through a reduction of the phloem influx (Morandi et al., 2011).

\section{Effect of girdling on sap flow dynamics through a tomato peduncle}

In Fig. 4A and B, the dynamics of sap flow through a girdled peduncle are displayed for the light and shade compartment, respectively. These dynamics indicate that xylem influx decreases during the day. This corresponds to results obtained by Guichard et al. (2005) based on the difference in growth rate between intact, girdled and detached fruits. A distinct inverse relationship between the measured xylem influx dynamics and the stem sap flow seems to exist (Fig. 4C and D). This can be explained by the fact that when sap flow increases, the total xylem water potential in the stem reaches more negative values (Fig. 4E and F), thereby reducing the water potential gradient between the stem and the fruits, and as such, the driving force for xylem water influx. In the afternoon, however, xylem influx appeared to increase, despite the low water potential in the stem. Possibly, high fruit transpiration rates, resulting from the high VPD in both compartments (2-3 $\mathrm{kPa})$, might have lowered the fruit water potential, thereby restoring the water potential gradient between the fruits and the stem and promoting xylem influx. 
When comparing xylem influx dynamics (Fig. 4A and B) with total influx dynamics (Fig. 3A and B), a contrasting pattern can be seen. This indicates that phloem influx, must be significantly larger than xylem influx during the day, resulting in an increased total influx during daytime. Indeed, previous girdling studies demonstrated similar results (Ehret \& Ho, 1986; Guichard et al., 2005), however our data represent a first direct measurement of the xylem influx with a sensor installed on the truss peduncle. The different pattern in sap flow dynamics after girdling also suggest that phloem and xylem did not work in an additive way. Apparently, the xylem did not, or at least not completely, substitute for the loss of water influx after blocking the phloem influx.

Measured sap flow dynamics $\left(\left(\mathrm{K}+\mathrm{dT}_{\mathrm{s}-\mathrm{a}}\right) \mathrm{dT}_{\mathrm{a}}{ }^{-1}\right)$ are, however, depending on the positioning of the thermocouples on the insulation tape. A deviation in this positioning might have large implications for the measured dynamics. For instance, for the sensor on the girdled truss in the shade compartment (Fig. 4B), T2 was positioned slightly closer to the heater and negative sap flow dynamics (backflow) were measured (Fig. 4B), because T2 was at a higher temperature due to the closer positioning to the heater element. Fruits on this truss were still slightly growing, indicating that water influx took place. Therefore, a robust construction of the sensor is needed. Additionally, a relation should be developed to link sap flow dynamics to absolute sap flow values. Nevertheless, this sensor has great potential for the measurement of sap flow through small plant parts and will surely help to finally resolve the controversy on water influx into developing fruits.

\section{CONCLUSIONS}

A mini HFD sensor was developed and tested for its potential to provide direct measurements of sap flow through a tomato peduncle. Sensor dynamics corresponded well with calculated sap influx based on fruit growth data and estimated transpiration. The dynamics of xylem influx through girdled trusses were successfully measured with the mini HFD sensor and demonstrated a close link to the total xylem water potential in the stem. An increased robustness and a relation to link the dynamics to actual sap flow rates are, however, necessary in the future.

\section{ACKNOWLEDGEMENTS}

The authors wish to thank Philip Deman, Geert Favyts and Thomas Vandeputte for technical support and IWT and the Special Research Fund of Ghent University (B.O.F.) for funding.

\section{Literature cited}

Clearwater M.J., Luo Z., Mazzeo M., Dichio B. An external heat pulse method for measurement of sap flow through fruit pedicels, leaf petioles and other small-diameter stems. Plant Cell Environ 32: 1652-1663.

Cuartero J. and Fernandez-Munoz R. 1999. Tomato and salinity. Sci Hort 78: 83-125.

De Swaef T., Verbist K., Cornelis W. and Steppe K. 2012. Tomato sap flow, stem and fruit growth in relation to water availability in rockwool growing medium. Plant Soil 350: $237-252$.

Ehret D.L. and Ho L.C. 1986. Effects of osmotic potential in nutrient solution on diurnal growth of tomato fruit. J Exp Bot 37: 1294-1302.

Guichard S., Gary C., Leonardi C. and Bertin N. 2005. Analysis of the growth and water relations of tomato fruits in relation to air vapor pressure deficit and plant fruit load. Journal of Plant Growth Regulation 24: 201-213. 
Ho L.C., Grange R.I. and Picken A.J. 1987. An analysis of the accumulation of water an dry matter in tomato fruit. Plant Cell Environ 10: 157-162.

Johnson R.W., Dixon M.A. and Lee D.R. 1992. Water relations of the tomato during fruit growth. Plant Cell Environ 15: 947-953.

Leonardi C., Baille A. and Guichard S. 1999. Effects of characteristics and climatic conditions on tomato transpiration in a greenhouse. J Hort Sci Biotech 74: 748-756.

Mitchell J.P., Shennan C. and Grattan R. 1991. Developmental changes in tomato fruit composition in response to water deficit and salinity. Physiol Plant 83: 177-185.

Morandi B. Zibordi M., Losciale P., Manfrini L., Pierpaoli E. and Grappadelli L.C. 2011. Shading decreases the growth rate of young apple fruit by reducing their phloem import. Sci Hort 127: 347-352.

Nadezhdina N., Čermák J. and Nadezhdin V. 1998. Heat field deformation method for sap flow measurements. In: Čermák J., Nadezhdina N. (Eds.), Proceedings of the 4th International Workshop on Measuring Sap Flow in Intact Plants. Publishing House of Mendel University, Czech Republic, pp. 72-92.

Nadezhdina N., Vandegehuchte M.W. and Steppe K. 2012. Sap flux density measurements based on the heat field deformation method. Trees DOI 10.1007/s00468-012-0718-3.

Pearce B.D., Grange R.I. and Hardwick K. 1993. the growth of young tomato fruit. II. Environmental influences on glasshouse crops grown in rockwool or nutrient film. $\mathrm{J}$ Hort Sci 68: 13-23.

Plaut Z., Grava A., Yehezkel C. and Matan E. 2004. How do salinity and water stress affect transport of water, assimilates and ions to tomato fruits? Physiol Plant 122: 429-442.

Sakuratani T., Aoe T. and Higuchi H. 1999. Reverse flow in roots of Sesbania rostrata measured using the constant power heat balance method. Plant, Cell Environ 22: 1153-1160.

Smith D.M., Jackson N.A., Roberts J.M. and Ong C.K. 1999. Reverse flow of sap in tree roots and downward siphoning of waer by Grevillea robusta. Funct Ecol 13:256-264.

Van Bavel M.G. and van Bavel C.H.M. 1990. Dynagage installation and operation manual. Dynamax Inc., Houston, TX, USA.

van den Honert T.H. 1948. Water transport in plants as a catenary process. Far Soc Disc 3: $146-153$.

Windt C.W., Gerkema A. and Van As H. 2009. Most water in the tomato truss is imported through the xylem, not the phloem: a nuclear magnetic resonance flow imaging study. Plant Physiol 151: 830-842. 


\section{Figures}

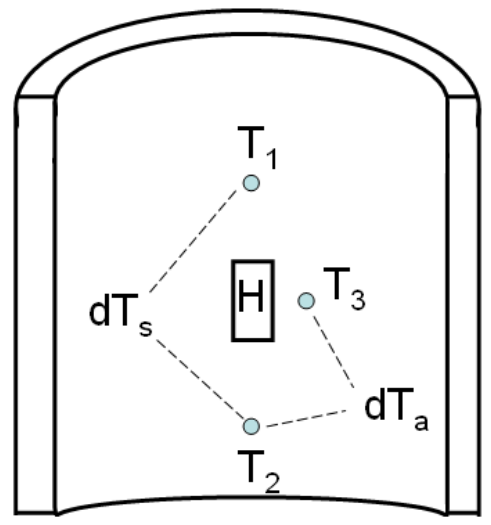

Fig. 1. Schematic of the non-invasive heat field deformation sensor, consisting of a heater element and three thermocouples $\left(\mathrm{T}_{1-3}\right)$, attached on rubber foam insulation tape. The heater element $(\mathrm{H})$ is providing a continuous heat supply and the thermocouples measure two temperature differences: the symmetrical temperature difference $\left(\mathrm{T}_{\mathrm{s}}\right)$ and the asymmetrical temperature difference $\left(\mathrm{dT}_{\mathrm{a}}\right)$.
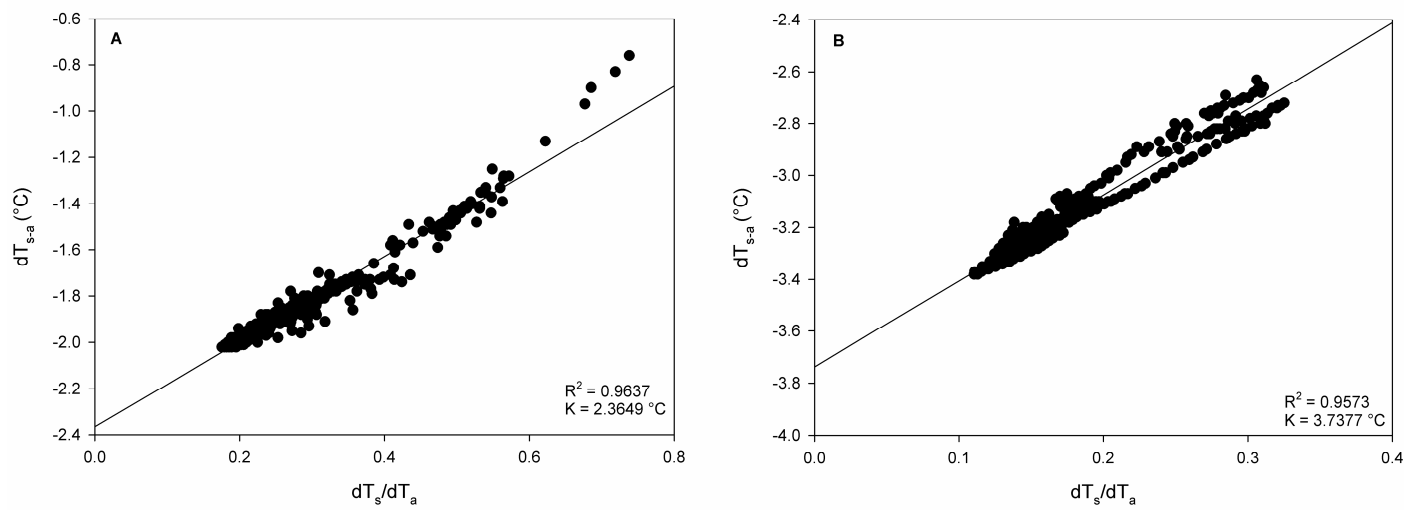

Fig. 2. Relation between calculated temperature difference $\mathrm{dT}_{\text {s-a }}\left({ }^{\circ} \mathrm{C}\right)$ and the ratio between $\mathrm{dT}_{\mathrm{s}}$ and $\mathrm{dT}_{\mathrm{a}}$ measured on a tomato peduncle in the light compartment $(\mathrm{A})$ and the shade compartment (B). The $\mathrm{K}$ values were determined as the intersection of the linear regression on the y-axis and equal $2.3649{ }^{\circ} \mathrm{C}$ and $3.7377{ }^{\circ} \mathrm{C}$ in the light and the shade compartment, respectively.

Fig. 3. Comparison between the HFD dynamics $\left(\mathrm{K}+\mathrm{dT}_{\mathrm{s}-\mathrm{a}}\right) \cdot \mathrm{dT}_{\mathrm{a}}^{-1}$ (grey dots) and calculated truss influx (black line) into an intact tomato truss with three fruits: A. Light compartment; B. Shade compartment. Graphs cover a 2-day period on the $25^{\text {th }}$ and the $26^{\text {th }}$ of May 2011. Dark periods are indicated with grey bars.
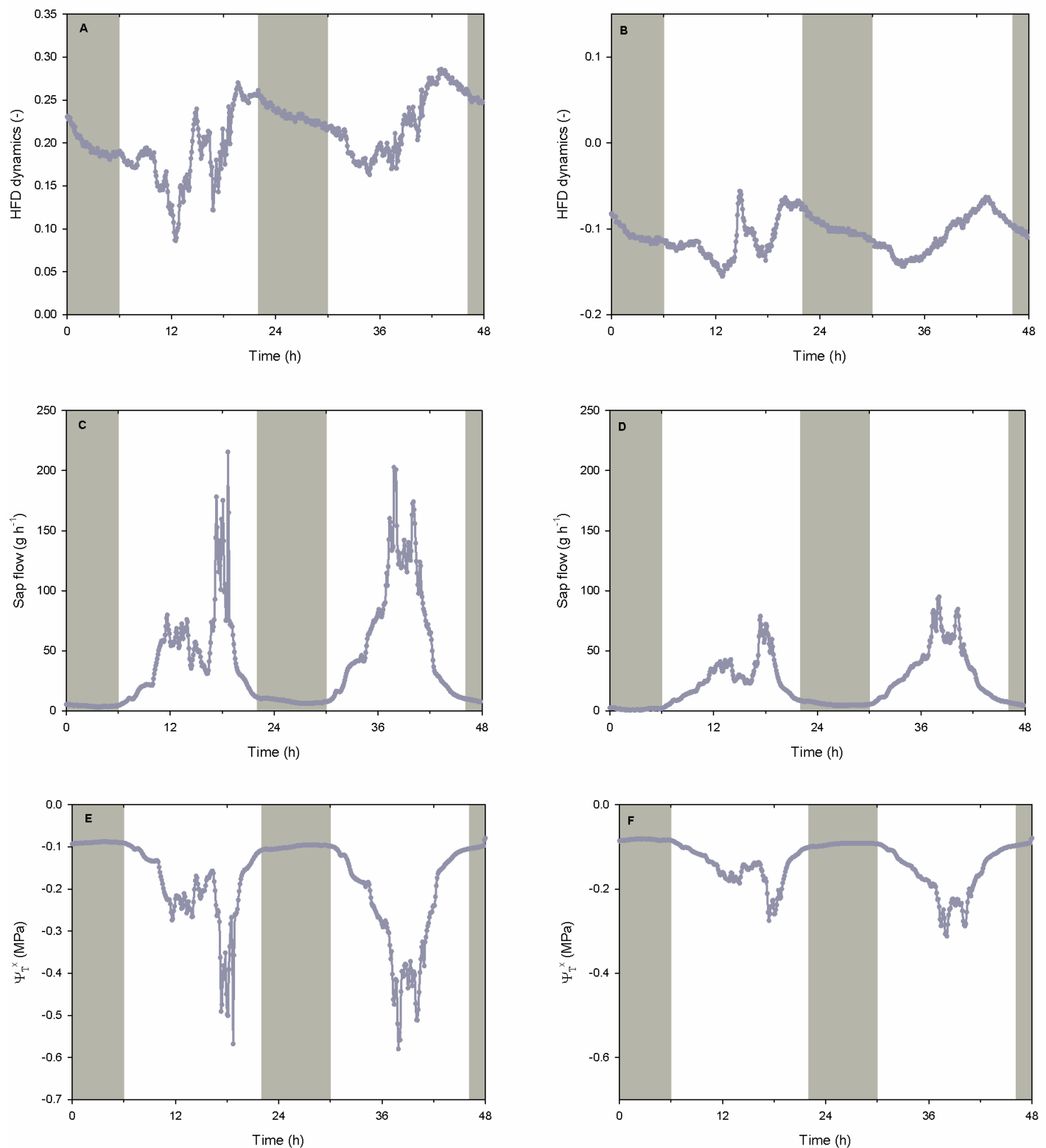

Fig. 4 HFD dynamics $\left(\mathrm{K}+\mathrm{dT}_{\mathrm{s}-\mathrm{a}}\right) \cdot \mathrm{dT}_{\mathrm{a}}{ }^{-1}$ of sap flow into a girdled tomato truss with three fruits in the light (A) and the shade (B) compartment on 27 and 28 May 2011; Sap flow of a plant in the light (C) and the shade compartment (D) on 27 and 28 May 2011; Total xylem water potential in the stem in the light (E) and the shade compartment (F) on 27 and 28 May 2011. Dark periods are indicated with grey bars. 